\title{
Electrochemical Impedance Spectroscopy Study of Lime Soil and Interpretation of the Results
}

\author{
Zhiwei Chen, Pengju Han", Bin He ${ }^{* *}$, Funan Sun, Xiangling Bai, Xinyu Liu, Yuting Wang \\ College of Civil Engineering, Taiyuan University of Technology, Taiyuan, 030024, China \\ *E-mail: 13834569544@163.com \\ ***-mail: hebin@tyut.edu.com
}

doi: $10.20964 / 2021.08 .11$

Received: 6 April 2021 / Accepted: 29 May 2021 / Published: 30 June 2021

In this study, data measured by the electrochemical impedance spectroscopy (EIS) method were used to assess the shear strength and unconfined compressive strength of lime soil. Two equivalent circuit models, $R \mathrm{~s}(Q(R \mathrm{ct} W)$ and $R \mathrm{~s}(Q R \mathrm{ct})$, were proposed to explain the EIS results in terms of the physical properties and chemical reactions in lime soil. The experimental results suggest that the peak phase angle value in the Bode plots has a linear relationship with the internal friction angle. The equivalent circuit element parameter $R$ ct is positively correlated with cohesion and unconfined compressive strength, while $Q$ is negatively correlated with these variables. The relationships between cohesion and $\ln (R \mathrm{ct} / Q)$ and between unconfined compressive strength and $\ln (R \mathrm{ct} / Q)$ all show good linear correlations. Hence, the peak phase angle and equivalent circuit element parameters $(R \mathrm{ct}, Q)$ can be applied to assess and predict the shear strength and unconfined compressive strength of lime soil.

Keywords: Electrochemical impedance spectroscopy (EIS); Shear strength; Unconfined compressive Strength; Lime soil

\section{$\underline{\text { FULL TEXT }}$}

(C) 2021 The Authors. Published by ESG (www.electrochemsci.org). This article is an open access article distributed under the terms and conditions of the Creative Commons Attribution license (http://creativecommons.org/licenses/by/4.0/). 